\title{
Autoridade e Legitimidade em Estratégia
}

\section{Authority and Legitimacy in Strategy}

\author{
Alexandre Faria* \\ Takeyoshi Imasato**
}

\section{Resumo}

Autoridade e legitimidade são conceitos fundamentais em estratégia. A autoridade do estrategista - em especial o estrategista da grande empresa - costuma se basear na validade legítima de sua posição, de suas práticas e do tipo de conhecimento usado. A área de estratégia, por sua vez, costuma fornecer bases legítimas para a autoridade do estrategista e também ser legitimada pelo estrategista e suas práticas. Essa combinação de características ajuda a explicar a extraordinária expansão território-internacional da grande empresa e da área de estratégia nas últimas décadas e também por que a autoridade de estrategistas e das grandes empresas vem sendo amplamente desafiada na era da globalização. Com base na contribuição de Max Weber, este artigo mostra a importância da dimensão territóriointernacional da autoridade e da legitimidade para estrategistas e para a área de estratégia. Os autores argumentam que o conhecimento produzido nos EUA é problemático no Brasil, porque não reconhece questões de poder e política ressaltadas por Weber nem os diferentes tipos de estrategistas que fazem parte de economias emergentes. Ao final, os autores sugerem como e por que a área de estratégia no Brasil pode ajudar a compreender e a construir a autoridade legítima de estrategistas em economias emergentes.

Palavras-chaves: Estratégia; Legitimidade; Autoridade; Economias Emergentes.

\begin{abstract}
Authority and legitimacy are key concepts in strategy. The authority of the strategist - in special the strategist of the big corporation - is based on the legitimate validity of his position, practices, and the type of knowledge he or she uses. The field of strategy provides bases of legitimacy for the authority of strategists and also is legitimated by strategists. These characteristics help explain the extraordinary territorial-international expansion of both big corporations and the field of strategy in the last decades and also why the authority of the strategist is being challenged in the age of globalization. Based on the work of Max Weber this article shows the importance of the territorial-international dimension of authority and legitimacy for both strategists and the field of strategy. The authors argue that the knowledge produced in US is problematic because it doesn't recognize power and political issues pointed out by Weber, nor the different types of strategists that are typical in emerging economies. The authors suggest in the end how and why the field of strategy in Brazil can help comprehend and construct legitimate authority of strategists in emerging economies.
\end{abstract}

Key-words: Strategy; Legitimacy; Authority; Emerging Economies.

\section{Introdução}

A área de estratégia é profícua na construção e no uso de modelos relacionados ao conceito de autoridade. Esta costuma garantir aos estrategistas o direito de exercer poder sobre mercados, instituições e organizações. Apesar de a literatura especializada privilegiar os interesses e necessidades dos estrategistas de grandes empresas, esta característica se aplica a diferentes tipos de estrategistas - tais como executivos, políticos,

\footnotetext{
- Alexandre Faria, PhD em Administração de Empresas pela University of Warwick, Reino Unido. Professor Adjunto na Escola Brasileira de Administração Pública e de Empresas da Fundação Getulio Vargas - EBAPE-FGV e Pesquisador do CNPq Endereço: Praia de Botafogo, 190 - sala 535 - Botafogo - Rio de Janeiro/RJ Brasil - CEP: 22250-900.E-mail: afaria@fgv.br

“ Takeyoshi Imasato, MsC em Administração pela Universidade Federal do Rio Grande do Sul - UFRGS. Doutorando na Escola Brasileira de Administração Pública e de Empresas da Fundação Getulio Vargas - EBAPE-FGV. Endereço: Praia de Botafogo, 190 - sala 538 - Botafogo - Rio de Janeiro/RJ - Brasil - CEP: $22250-900$. E-mail: timasato@fgv.br
} 
líderes sociais etc. -, de organizações - tais como empresas privadas, organizações públicas, e organizações não-governamentais -, e de sistemas de economia política - tais como as economias tidas como mais desenvolvidas, economias emergentes, e economias tidas como menos desenvolvidas.

O uso do poder sem autoridade é associado a termos problemáticos, tais como autoritarismo ou abuso (SINGHVI, 1969). Ainda que esses termos praticamente inexistam na literatura de estratégia, é importante ressaltar que autoridade não dura para sempre nem funciona em todos os lugares da mesma forma. Temos visto nos anos recentes, por exemplo, ataques contundentes à autoridade da grande empresa e de seus estrategistas. Ativistas e organizações não governamentais vêm protagonizando esse movimento em diversos países.

Esse quadro é particularmente desafiante em economias emergentes, por três grandes razões. A primeira razão é que a maioria dos ataques à autoridade das grandes corporações diz respeito à atuação das mesmas em economias emergentes (FOX, 2004). A segunda razão é que as economias emergentes são de central importância para a expansão das grandes corporações na era da globalização (BRUGMANN; PRAHALAD, 2007; WORDEN, 2003; SINHA, 2005). A terceira razão é que as grandes corporações de economias emergentes deverão exercer um papel central para o futuro da economia global e do capitalismo (ARBIX et al., 2002).

Essas questões ajudam a explicar o interesse crescente da literatura de estratégia dos EUA, tanto por questões sociais e políticas quanto por desenvolver conhecimento acadêmico em economias emergentes (D'AVENI, 2004; BARON, 2005; WRIGHT et al., 2005; KHANNA et al., 2005; KHANNA; PALEPU, 2006; PORTER; KRAMER, 2006). Elas também ajudam a explicar a reação recente da academia na Europa à autoridade do conhecimento produzido, na área, pelos EUA (i.e., WHITTINGTON, 2004; TARKEY; TEMPEST, 2004).

Liderança, direção, descentralização, hierarquia, entre outros conceitos da literatura de estratégia, são sinônimos ou eufemismos de poder com autoridade (HÖPFL, 1999). A literatura especializada falha em reconhecer que a autoridade do estrategista se apóia em bases sociais de legitimidade, ou seja, que a autoridade do estrategista se apóia em uma base ampla - de natureza institucional, legal ou de costumes -, que transcende as fronteiras da organização.

Uma das principais bases de legitimidade para o estrategista é o conhecimento acadêmico. Isso ajuda a explicar a liderança dos EUA na área de estratégia, a extraordinária expansão territorial da academia dos EUA na era da globalização (BRODY, 2007), as críticas correspondentes que vêm sendo produzidas na Europa (WHITTINGTON et al., 2003), e também a escassez de literatura focada em autoridade legítima na área de estratégia.

Este ensaio mostra que os conceitos de autoridade e legitimidade devem ser problematizados pela área de estratégia no Brasil. Dentre as principais justificativas, destacamos duas: (a) a liderança histórica dos EUA na produção de conhecimento acadêmico na área de estratégia passou a ser questionada na Europa na era da globalização; e (b) a autoridade legítima da liderança do EUA ainda não foi questionada sob a perspectiva de economias emergentes e de seus estrategistas. Correspondentemente, o principal objetivo deste ensaio é mostrar como e por que os conceitos de autoridade e legitimidade são importantes para estrategistas e para a área de estratégia no Brasil.

Este ensaio está dividido em mais cinco seções. Na próxima os autores mostram a importância da compreensão de autoridade e legitimidade na área de estratégia sob a perspectiva de economias emergentes e de seus estrategistas. Na terceira seção, é feita uma revisão crítica da literatura focada em legitimidade e autoridade por meio do resgate do trabalho de Max Weber. Na seção subsequiente os autores apresentam a importância do debate protagonizado pelos modelos de planejamento estratégico e de gestão estratégica na literatura produzida nos EUA para a construção da autoridade legítima do estrategista da grande empresa. Na quinta seção, os autores mobilizam os argumentos de Weber para explicar por que a construção da legitimidade de estrategistas no Brasil, como uma economia emergente, deve ser priorizada pela área de estratégia. Na última seção, são apresentadas sugestões para a produção de conhecimento em estratégia no Brasil. 


\section{Legitimidade e autoridade em estratégia}

O poder do estrategista é mais efetivo quando exercido não com força, mas sim com autoridade e legitimidade. De fato, autoridade e legitimidade têm sido desafios centrais para as grandes empresas e seus estrategistas. Uma primeira razão é que legitimidade pode tanto fornecer quanto retirar as bases para a autoridade dos estrategistas. Uma segunda razão é que as bases de legitimidade para a autoridade dos estrategistas não residem exatamente dentro da organização nem duram para sempre.

$\mathrm{Na}$ era da globalização, apesar da timidez da literatura de estratégia quanto a essa questão, a gestão da legitimidade e da autoridade do estrategista vem ganhando crescente importância (ASHFORTH; GIBBS, 1990). A principal razão é o crescente volume de ataques à autoridade dos estrategistas das grandes empresas (DAVIS, 2004; COWLING; TOMLINSON, 2005). Segundo a McKinsey, o quadro é extremamente preocupante. Analistas desta importante empresa de consultoria argumentam que já é hora de os estrategistas da grande empresa assumirem uma posição política mais ativa, visto que tais ataques podem tanto destruir a reputação das grandes corporações quanto alterar substancialmente as arenas competitivas em que elas estão inseridas.

[...] é hora de os executivos chefes serem menos reticentes e tomarem a dianteira: eles têm muito o que adicionar à discussão, e é do interesse estratégico das suas empresas, dos negócios e da economia global que eles o façam. Forças sociais e políticas podem alterar a estrutura de uma indústria, danificar ou ressaltar a reputação de uma empresa, e criar oportunidade de mercados para direcionar necessidades sociais e preferências de novos consumidores. Além disso, os executivos estão particularmente bem posicionados para articular e ajudar a resolver complexos trade-offs inerentes aos grandes temas sociais, desde mudança climática até cuidados com saúde e pobreza. O mundo dos negócios, e particularmente dos grandes negócios, tem um papel vital na resolução desses imensos desafios. (DAVIS, 2006, p. 4)

Os ataques à autoridade do estrategista da grande empresa têm vindo de diversos territórios e vêm sendo mobilizados principalmente por organizações não governamentais, ativistas e instituições da sociedade civil (PORTER; KRAMER, 2006; FOX, 2004). Além de terem o mesmo alcance global das grandes corporações, esses agentes gerenciam de forma efetiva o binômio autoridade-legitimidade. Esse quadro é mais intenso e preocupante em economias emergentes, e isso ajuda a explicar por que reputação tornou-se uma palavra-chave para as grandes corporações nesses novos mercados (BRUGMANN; PRAHALAD, 2007; MAHAJAN; BANGA, 2006). Ainda que esse problema não tenha chamado a atenção de pesquisadores em economias emergentes, é importante ressaltar que as corporações de economias emergentes e de economias tidas como menos desenvolvidas são mais afetadas do que as de economias mais desenvolvidas por esse cenário de disputas (AULAKH et al., 2000).

Uma primeira questão importante sobre a gestão de legitimidade e autoridade é que a globalização ampliou de forma extraordinária o contexto no qual a grande empresa se insere. Uma das principais características da globalização é a eliminação de limites geográficos para as grandes empresas. Isso traz novas complexidades. Em certos países ou regiões, um estrategista de determinada etnia ou religião pode exercer sua autoridade sobre uma pessoa de outra etnia ou religião dentro da empresa, sem que haja reações negativas, porque o sistema legal ou o conjunto de normas sociais e valores locais assim o permite. Esse mesmo tipo de prática pode ser tido como ilegítimo em outros países, inclusive no país-sede dessas empresas.

Uma segunda questão é que os valores sociais, as expectativas e as percepções de diferentes constituintes, ou grupos específicos de constituintes, em determinado país ou região, costumam ser contraditórios (SCHOCKER; SETHI, 1974). Essa característica exige do estrategista um conhecimento aprofundado dos diferentes países ou regiões em que as grandes empresas operam. Uma terceira questão importante é que dentro de um mesmo país ou região as bases de legitimidade costumam mudar, assim como as preferências dos diferentes constituintes ou grupos de constituintes (ROPER, 2005). Essa característica tornou-se mais acentuada na era da globalização devido às diversas origens das grandes empresas atuando em determinado país. Isso exige do estrategista uma extraordinária capacidade de prever e gerenciar mudanças em diversos países, inclusive nos países-sede. 
Além dos ataques recentes, essas questões deixam claro que a gestão da autoridade e legitimidade ficou extremamente desafiante para o estrategista das grandes empresas - o que ajuda a explicar a crescente importância das estratégias corporativas de comunicação (ROPER, 2005). O crescente alcance e poder das grandes empresas na era da globalização e a crescente visibilidade e vulnerabilidade dessas organizações em relação a diferentes constituintes ou stakeholders, os quais mobilizam demandas distintas ou divergentes, se transformaram em tópicos de central importância para as grandes empresas (D'AVENI, 2004; BARON, 2005; PORTER; KRAMER, 2006).

Nesse novo cenário, estrategistas de grandes empresas vêm enfrentando três desafios principais: (a) construir novas bases de legitimidade e suprimir certas bases de legitimidade em determinado país (ou território), sem provocar reações contrárias dos stakeholders mais afetados; (b) adaptar-se a contextos e a bases locais de legitimidade que são tidas como ilegítimas nos países-sede; e (c) desafiar as bases 'estrangeiras' de legitimidade que são trazidas para seus territórios principais pelas grandes empresas de diversas origens.

Um dos principais recursos para a gestão da legitimidade e da autoridade do estrategista na era da globalização é o trânsito de influências políticas, discursos e idéias de um contexto ou território para outro (FARIA, 2006). Um recurso central para o estrategista da grande empresa nesse contexto de disputas é o conhecimento acadêmico na área (WHITTINGTON et al., 2003; STARKEY; TEMPEST, 2004; ROPER, 2005).

A literatura de estratégia é tímida quanto a essas questões, especialmente nos EUA. A principal razão é que seus pesquisadores tendem a desprezar conceitos relacionados a poder e à política (ver BARON, 2005; BAILEY, 2001). Por diversas razões, poder e política tornaram-se ilegítimos na literatura dominante de estratégia produzida nos EUA (MINTZBERG et al., 2000) ainda que a área, como conjunto de práticas e campo de conhecimento acadêmico, seja intimamente relacionada a poder e política (KNIGHTS; MORGAN, 1991; LEVY et al., 2003).

De fato, podemos argumentar que estratégia e conhecimento são conceitos intimamente relacionados a poder e política. Isso ajuda a explicar tanto o domínio dos EUA na área de estratégia, como a ausência de questões de poder e de política na literatura dominante. Legitimidade e autoridade são particularmente importantes para o estrategista porque ajudam a tornar 'invisível' o poder para aqueles sobre os quais ele é exercido. Esse efeito, o qual se aplica também sobre aqueles que exercem poder, costuma ser obtido por meio da produção e difusão de certos discursos e tipos de conhecimento acadêmico (FARIA, 2006; ROPER, 2005) ${ }^{1}$.

A importância do conhecimento acadêmico para tornar invisíveis as questões de poder e política ajuda a explicar não apenas a liderança histórica dos EUA na área de estratégia, mas também os questionamentos feitos recentemente na Europa acerca da validade dessa posição (KNIGHTS; MORGAN, 1991; PETTIGREW et al., 2003; HAMBRICK, 2004). Esse quadro também ajuda a explicar o crescente interesse de grandes firmas de consultoria e de acadêmicos dos EUA em promover a construção e a disseminação de conhecimento em e para estratégia em economias emergentes (BRUGMANN; PRAHALAD, 2007; SINHA, 2005; KHANNA et al., 2005).

Em termos gerais, esse quadro não é muito favorável em e para economias emergentes. Um grande obstáculo para a problematização de autoridade e legitimidade em estratégia é que a literatura contemporânea no campo da administração não reconhece a dimensão território-internacional da autoridade que foi problematizada por Weber.

Enquanto teóricos clássicos como Max Weber devotaram atenção considerável à dimensão territorial da autoridade e do poder, a investigação política nos dias atuais está mais propensa a focar nas relações de poder dentro de instituições e entre as principais classes sociais do que em relações de poder que se estendem através dos territórios. (HUTCHCROFT, 2001, p. 24)

Essa lacuna é de central importância para e em economias emergentes. É inegável, por exemplo, que, em diversos países, pessoas e instituições atribuíram autoridade legítima à grande corporação a partir do momento em que a literatura de estratégia produzida nos EUA foi amplamente disseminada internacionalmente. Em muitos desses países havia desconfiança, assim como também houvera nos EUA até meados do século passado, 
quanto ao poder das corporações em relação ao Estado e à sociedade. Na era da globalização, esse quadro não é muito diferente.

Com base na atribuição de legitimidade à economia centrada na grande empresa e de autoridade legítima aos estrategistas dessas organizações nos textos acadêmicos, estratégia alcançou um primeiro estágio de legitimidade social em alguns países. Mais adiante, estratégia acabou sendo transformada em filosofia de gestão em diversos outros países. Na era da globalização, esse processo ficou ainda mais preocupante. Pesquisadores da área argumentam que é urgente que estratégia, como filosofia de gestão, seja incorporada em economias emergentes por organizações públicas, empresas de pequeno e médio porte, organizações sem fins lucrativos, e até mesmo organizações não governamentais.

Em grande parte, esse processo é explicado pelo temor de que economias emergentes possam promover algum tipo de capitalismo que não se alicerce nas noções de livre mercado e de grande empresa (CHANG, 2002; BURAWOY; LUKACS, 1985). Segundo Van Agtmael (2007, p. 12), a economia global que vem sendo liderada pelos EUA tende "a voltar ao ponto em que se encontrava antes da Revolução Industrial, quando a Índia e a China eram grandes potências econômicas". Esse temor foi ressaltado recentemente nos EUA por acadêmicos, tanto de direita quanto de esquerda (JARVIS, 2006).

Um dos desafios para economias emergentes e para seus estrategistas é que a literatura produzida nos EUA associa a noção de estrategista exclusivamente ao manager (gerente) da grande empresa. ${ }^{2}$ Essa bagagem cria dificuldades para o reconhecimento de outros tipos de estrategistas, tais como políticos, administradores públicos, líderes sociais, diplomatas, ativistas etc. Esses 'outros' estrategistas são de central importância nas (e para as) dinâmicas sócio-políticas que caracterizam os mercados e as estratégias de grandes empresas em economias emergentes (CHANG, 2002; BURAWOY; LUKACS, 1985). Esses outros tipos de estrategistas e as dinâmicas correspondentes, ainda que desafiem o modelo de economia política dominate na era da globalização, são de central importância para o desempenho de empresas de economias emergentes no mercado global (CRAIG; PORTER, 2005).

Cabe aqui destacar que a área de estratégia foi construída nos EUA, nos anos 1960, sem provocar muitos questionamentos em outros países. Na era da globalização, esse quadro mudou. Principalmente por causa de escândalos corporativos e dos ataques crescentes à autoridade da grande corporação e dos EUA, temos assistido a manifestações de preocupação quanto aos impactos sociais e econômicos da área (WHITTINGTON et al., 2003) e também quanto aos rumos da pesquisa (SCHERER, 1998; BIGNETTI; PAIVA, 2002; BERTERO et al., 2003; HAMBRICK, 2004; WHITTINGTON, 2004) e do ensino (HOLAN; MINTZBERG, 2004). ${ }^{3}$

A literatura especializada na área de estudos organizacionais (PFEFFER; SALANCIK, 2003; OLIVER, 1991; SUCHMAN, 1995), que costuma ser mobilizada por autores da área de estratégia para a condução dos debates mais complicados, aborda legitimidade sob uma perspectiva limitada, focada nas relações intra- e interorganizacionais. Essa literatura não dá a devida atenção aos aspectos territoriais da autoridade e da legitimidade enfatizados por Weber. Correspondentemente, essa literatura não é capaz de problematizar a importância política, econômica e ideológica do processo de difusão do conhecimento em administração made in USA (MILLS; HATFIELD, 1999; LOCKE, 1996).

A construção de conhecimento relevante para estrategistas de (e em) economias emergentes demanda uma postura crítica com relação ao conhecimento acadêmico produzido nos EUA. ${ }^{4}$ Para isso, os autores resgatam, na seção seguinte, a contribuição de Max Weber.

\section{Compreendendo autoridade e legitimidade}

O conceito de legitimidade vem sendo tratado por diversas áreas do conhecimento, tais como Ciência Política (FAORO, 1982; RICHTER, 1982; SCAFF, 1983; ANSELL, 2001), Direito (DYZENHAUS, 2001; FALLON, 2005), Sociologia (DIMAGGIO; POWELL, 1983; DELLA FAVE, 1986), Psicologia (TYLER, 2006) e Administração (OLIVER, 1991; PFEFFER; SALANCIK, 2003; SUCHMAN, 1995). Cada área adota 
abordagens e posições distintas, o que torna problemático o propósito de conceituar legitimidade, com precisão (ANSELL, 2001), na área de estratégia.

O principal problema em estratégia é que área não reconhece questões relacionadas a poder e política. Uma análise histórica mostra que legitimidade tornou-se um conceito importante primeiramente na área de Ciência Política. A Revolução Francesa, que foi marcada pela ruptura política com o regime de monarquia absolutista, necessitava de justificativas para estabelecer a autoridade da nova ordem. $\mathrm{O}$ novo regime desafiava o velho regime (RICHTER, 1982; SCAFF, 1983) em um contexto político complicado que levou ao estabelecimento do Estado Moderno. Nesse período de disputas em que a Revolução Industrial e a ascensão do capitalismo protagonizavam um processo de transformação profunda das sociedades ocidentais (WEBER, 2005), havia a necessidade de novas bases de legitimidade que garantissem a autoridade do novo regime.

Nesse contexto histórico, Max Weber foi pioneiro na elaboração teórico-conceitual de legitimidade e autoridade sob uma perspectiva que se baseava em questões de poder e política. Weber elaborou um arcabouço que permite a compreensão de como a autoridade provoca tanto a manutenção quanto a transformação de estruturas sociais. Segundo Weber, a autoridade (ou, se o leitor preferir, dominação), como ação social, ${ }^{5}$ se concretiza quando há obediência (WEBER, 2004). Por sua vez, a vontade de obedecer resulta tanto de uma habituação inconsciente como de ponderações conscientes, as quais estão intimamente relacionadas ao conceito de legitimidade.

Influenciado pelo contexto de emergência do capitalismo, Weber (2004) teorizou os principais mecanismos e dimensões envolvidas no processo de atribuição e aceitação de validade legítima de determinada ordem social.

A legitimidade, segundo o autor, pode ser construída de diferentes modos:

I - De modo puramente íntimo; e neste caso: 1) puramente afetiva - por entrega sentimental; 2) racional com relação a valores - pela crença em sua validade absoluta enquanto expressão de valores supremos geradores de deveres (morais, estéticos ou de qualquer outro tipo); 3) religiosa - pela crença de que de sua observância depende a salvação.

II - Também (ou somente) pela expectativa de determinadas conseqüências externas; ou seja, por uma situação de interesses; mas por expectativa de um determinado gênero. (Weber, 2004, p. 27)

A complexidade do trabalho de Weber e o fato de que o mesmo somente foi publicado após sua morte ajudam a explicar por que suas idéias não foram suficientemente exploradas pela literatura recente de administração. Um outro obstáculo é que Weber construiu suas bases teóricas por meio do uso de tipos ideais. ${ }^{6}$ A construção de um tipo ideal consiste em enfatizar determinados traços da realidade, fenômenos observáveis na vida social, e concebê-los na sua expressão mais pura (COHN, 1997). Os tipos ideais, que não são observáveis na realidade, visto que são utopias (WEBER, 1997), se baseiam no pressuposto "de que a realidade social só pode ser conhecida quando aqueles traços que interessam ao pesquisador são metodicamente exagerados, para em seguida se formular com clareza as questões relevantes sobre as relações entre os fenômenos observados" (COHN, 1997, p. 8).

Correspondentemente, as categorias 'puramente íntimo' e 'expectativas de determinadas consequiências' são úteis porque facilitam a análise empírica e a compreensão das ações sociais - que podem (e não necessariamente irão) garantir a legitimidade de determinada ordem social. A primeira categoria se refere a disposições individuais, 'puramente internas', que garantem a legitimidade de uma ordem. A categoria subseqüente está relacionada a disposições de interesses coletivos, "puramente externas", que conferem a legitimidade de uma ordem social em determinado contexto. A validade legítima de uma determinada ordem social, que confere certo sentido de orientação às ações e práticas sociais, criando estabilidade e regularidade às relações sociais, pode ser atribuída e instituída pelos atores de uma dada sociedade por diferentes meios (WEBER, 2004, p. 29):

a) Por méritos da tradição: validade do que sempre existiu;

b) Por uma crença afetiva (especialmente emotiva): validade do novo revelado ou do exemplar; 
c) Por uma crença racional segundo valores: vigência do que se tem como absolutamente valioso;

d) Pelo estatuído positivamente, em cuja legalidade se crê. Esta legalidade pode valer como legítima:

1) com base no pacto dos interessados; 2) com base na virtude da "outorga" a uma autoridade considerada legítima e da submissão correspondente.

Um dos elementos fundamentais para a compreensão da validade legítima de uma ordem social, segundo Weber, é a crença, ou seja, a convicção de que determinada ordem expressa o interesse coletivo em virtude de sua validade. A construção da autoridade legítima depende de e se baseia na crença e na convicção dessa validade. Estas criam as bases de uma relação de autoridade que parece prescindir da obediência forçada (ARENDT, 2000).

Weber (2004, p. 170) ressalta que um "determinado mínimo de vontade de obediência, ou seja, de interesse (externo ou interno) em obedecer, é essencial em toda relação autêntica de autoridade". A legitimidade de uma autoridade, desse modo, não é imposta unilateralmente. Ela necessita de algum grau de consentimento entre os seus constituintes para que seja válida. Mais especificamente, é necessária a crença de que a ordem correspondente expressa interesses individuais e coletivos.

É importante também ressaltar que, apesar de tudo, não é por meio da compreensão da crença que se compreende a autoridade legítima, segundo a perspectiva de ação social privilegiada pelo autor. A lealdade pode ser ardilosamente simulada por indivíduos, a despeito de suas crenças, valores íntimos ou expectativas de conseqüências externas. O próprio Weber (2004, p. 171) adverte que:

A "legitimidade" de uma dominação deve ser considerada somente como uma probabilidade, a de ser tratada praticamente como tal e mantida na proporção importante. Não se deve supor que a obediência [...] esteja orientada primariamente (nem sequer sempre) pela crença em sua legitimidade. A adesão pode ser fingida por indivíduos e grupos inteiros por razões de oportunidade, sendo praticada por causa de interesses materiais próprios, ou ser aceita como algo irremediável em virtude de debilidades individuais e desvalimento. Isso não é decisivo para a classificação de uma autoridade (ou dominação).

Há nuances nas relações sociais que limitam a possibilidade de se compreender como e por que determinada ordem social é legitimada. Conseqüentemente, não é tão fácil entender a autoridade apenas por aquilo que as pessoas crêem ou declaram acreditar. Parte do complexo processo que cria e reproduz a legitimidade de uma dada ordem social é 'invisível' e inacessível apenas pelo sentido dado ou conferido pelos seus constituintes. Correspondentemente, poder e política (WEBER, 2004; ARENDT, 2000), cultura (BROWN, 1994; HÖPFL, 1999), e ideologia (SHRIVASTAVA, 1986; FAORO, 1982) são necessários para a compreensão do processo de legitimação da autoridade na área de estratégia.

Com base no trabalho de Weber, o que está sendo sugerido aqui é que legitimidade e autoridade têm íntima relação com questões de poder e política e também com questões território-internacionais. Fronteiras territoriais costumam limitar o uso de poder por autoridades que são tidas como legítimas em outros contextos. Essa questão era central para a constituição do Estado moderno e para sua difusão internacional. A difusão da nova ordem para territórios que se opunham aos princípios e interesses do Estado moderno, era uma questão central para o trabalho de Weber.

Weber define o Estado moderno como a "comunidade humana que no interior de um determinado território - o conceito de 'território' é essencial na definição - reclama para si (com sucesso) o monopólio da coação física legítima" (2004, p. 1056). A autoridade do Estado moderno não era exercida por meio da força, mas sim por meio da legitimidade. Um dos principais recursos de legitimação na época foi o conhecimento científico. Isso ajuda a explicar por que Weber (2001, p. 55) argumenta que "[...] não existe ciência inteiramente isenta de pressupostos e [...] que ciência alguma tem condição de provar seu valor a quem lhe rejeite os pressupostos". 


\section{Análise histórica da construção da área de estratégia}

Não é correto argumentar que desenvolvimentos acadêmicos na área de administração são isentos de valores e interesses (ALVESSON; DEETZ, 2000; PRASAD, 2003). De fato, valores e interesses são questões centrais na história da ciência:

Tanto nas sociedades capitalistas como nas sociedades socialistas de Estado do Leste Europeu, a industrialização da ciência acarretou o compromisso desta com os centros de poder econômico, social e político, os quais passaram a ter um papel decisivo na definição das prioridades cientificas. (SANTOS, 2002, p. 34)

Ao longo da história da área de estratégia nos EUA (ou strategic management, como a área é conhecida nos dias atuais), entre as questões mais importantes, esteve a construção da autoridade do estrategista da grande empresa em três âmbitos: a) na grande empresa; b) na sociedade; (c) em outros territórios. O primeiro foco ajuda a explicar a construção e a difusão do modelo do planejamento estratégico (PE). Os focos seguintes, que coincidiram com um processo de intensa expansão internacional das grandes empresas dos EUA, ajuda a explicar a emergência do debate entre PE e gestão estratégica (GE) na literatura produzida nos EUA. Esse processo acadêmico-político é revisto nas subseções a seguir.

\subsection{A autoridade na era do planejamento estratégico}

O modelo de PE foi importante para a construção da autoridade do estrategista na grande empresa e na sociedade a partir dos anos 1960 nos EUA. O entendimento da importância do modelo exige uma análise histórica da área de management. Essa área emergiu no início do século XIX, vinculada à Revolução Industrial e à industrialização da economia (POLLARD, 1968), enfrentando considerável oposição. A essa época, o termo manager era usado de forma pejorativa. Quando muito, denominava uma posição de serventia (FOURNIER; GREY, 2000) ou de potencial traição. Correspondentemente, a construção da autoridade do manager nos EUA foi um processo sócio-político complexo. Wren (1994, p. 45) descreve esse período:

A julgar pelo desenvolvimento inicial da literatura, os gerentes assalariados, isto é, aqueles que trabalhavam na camada da administração abaixo do empreendedor, eram em geral trabalhadores analfabetos, promovidos em relação aos demais porque evidenciavam um grau de capacidades técnicas superiores ou tinham a habilidade de manter a disciplina. Tipicamente eles recebiam um pouco mais do que os trabalhadores em geral e na maioria das vezes eram atraídos para posições gerenciais porque isso lhes dava poder para contratar esposas e filhos para trabalhar na fábrica.

Após um tímido, mas promissor, começo, a autoridade do manager enfrentou um sério obstáculo nos EUA que viria a ajudar a promover a construção do modelo de PE. Em meados do século XX, o sistema de educação em management foi avaliado como extremamente deficiente nos EUA. Estudos patrocinados pelas Fundações Ford e Carnegie concluíram que as escolas de negócios não estavam atendendo às necessidades das grandes empresas em uma época em que o lema "o que é bom para a General Motors é bom para a América e viceversa" vigorava nos EUA. A deficiência era preocupante para as grandes empresas, que demandavam gerentes mais qualificados; para as escolas de negócios, que viam sua posição ameaçada dentro da universidade e da sociedade; e para o próprio país, que contava com as grandes empresas para a promoção de desenvolvimento.

A construção da autoridade do estrategista na grande empresa e na sociedade nos EUA, a partir desse momento crítico, demandou tanto a superação do significado negativo atribuído ao manager quanto a superação das desconfianças em relação ao crescente poder econômico e político dessas empresas nos EUA (LOCKE, 1996).

A Harvard Business School (HBS), por meio do uso de casos de ensino e a partir do trabalho de Chandler (1962; 1977), um dos pais da estratégia (ver Whittington, 2001), ajudou a construir a legitimidade e a autoridade do estrategista e da grande empresa por meio da difusão do princípio de que 'a estrutura segue a estratégia' e do conceito da 'mão visível' em suas atividades de educação e pesquisa em estratégia. Os livrostexto da área de estratégia, por exemplo, foram maciçamente exportados para diversos países naquela época, 
em paralelo à expansão territorial das grandes empresas dos EUA e do modelo de capitalismo praticado nos EUA (GILPIN, 2004).

Os estrategistas das grandes empresas eram descritos nos casos de ensino e nos livros-texto como legítimos substitutos da 'mão invisível', de acordo com uma ordem social made in USA denominada de capitalismo gerencial (ver Chandler, 1977; 1984). A autoridade atribuída ao estrategista nos textos acadêmicos e nas práticas correspondentes ajudou a aproximar as escolas de negócios às grandes empresas e a fazer com que a estratégia fosse transformada em disciplina "de fecho e de integração" no currículo da administração (STEINER; MINER, 1977, p. 4).

Os casos de ensino se transformaram em importante recurso de legitimação da autoridade do estrategista e da grande empresa dentro dos EUA e no exterior. Os casos atribuíam ao ambiente externo o papel de 'inimigo', enquanto a grande empresa e o estrategista desempenhavam o papel de 'mocinhos'. A sociedade, no final das contas, era a 'vítima' a ser protegida. Essa base de legitimação dava ao estrategista a autoridade para o uso de poder dentro da grande empresa e, correspondentemente, na sociedade.

As concepções de estratégia que ressaltam a manipulação (ou abuso) da sociedade ou do mercado pelas grandes empresas foram suprimidas devido à ampla difusão de textos que estabeleciam a crença de que a estratégia garante a (necessária) sobrevivência da grande empresa frente ao ambiente externo ameaçador. A "capacidade de adaptação (da grande empresa) a mudanças no ambiente" (ORGAN, 1971, p. 74) passou a ser sinônimo de estratégia e isso afastou a idéia de que as grandes empresas e seus estrategistas podem ser prejudiciais à sociedade ou ao Estado. Cabe ainda destacar que a forte influência da Guerra Fria sobre a academia dos EUA (MILLS; HATFIELD, 1999) ajuda a explicar por que o Estado foi particularmente preterido em relação à 'livre empresa' e ao 'livre mercado' na literatura de estratégia.

Casos de ensino em estratégia, produzidos em sua maioria pela HBS, descreviam situações de sucesso e atribuíam aos estrategistas e ao domínio da estratégia (mais especificamente, ao modelo de PE) a responsabilidade pelos resultados alcançados. Nesses textos, que eram exportados a um grande número de países, não eram citados erros ou falhas dos estrategistas. A lógica dos textos era muito simples e direta: quanto mais ameaçador o ambiente externo, mais importantes são os estrategistas e o modelo de PE para a grande empresa e, por conseguinte, para a sociedade.

O modelo de $\mathrm{PE}$ ajudou a tornar ilegítimos outros significados que eram atribuídos às estratégias de grandes empresas, tais como 'invasão' ou 'dominação'. De fato, o modelo de PE foi particularmente útil apara a internacionalização das grandes empresas dos EUA nas décadas de 1960 e 1970 e apara a difusão de ideologias made in USA (LOCKE, 1996). Nesse processo, o estrategista da grande empresa não estava sozinho. Para outros estrategistas dos EUA, e também para diferentes tipos de estrategistas no exterior, era fundamental construir naquela época uma nova base de legitimidade que garantisse esse grandioso processo de expansão territorial (MILLS; HATFIELD, 1999).

O modelo de PE, reproduzindo o modelo de comando militar que era legítimo nos EUA, na época, por causa do êxito na Segunda Guerra Mundial (BOURGEOIS; BRODWIN, 1984), ajudou a construir uma divisão hierárquica legítima entre implementadores e formuladores na grande empresa e também na interface entre matriz e subsidiárias. Essa base de legitimação funcionou bem até o final dos anos 1970, quando as crises do petróleo provocaram transformações geopolíticas que afetaram substancialmente a autoridade do estrategista da grande empresa, da área de estratégia, e dos EUA no contexto internacional.

As críticas ao modelo de PE surgiram no início da década de 1980. A noção de 'invasão japonesa' nos EUA teve central importância para o surgimento de uma abordagem crítica que ignorava as reações em diversos países, inclusive nos EUA, ao avanço do imperialismo americano. ${ }^{8}$ Influenciados por movimentos pródemocratização no mundo e por descrições sedutoras e apolíticas do 'milagre japonês', consultores e acadêmicos concluíram que os grandes conglomerados dos EUA não conseguiam competir com os japoneses por causa do caráter 'autoritário' do PE (i.e. PETERS; WATERMAN, 1983). 
A partir de então iniciou-se um acalorado debate entre os defensores do PE e os da gestão estratégica (GE) na literatura dos EUA. Gurus como Tom Peters e acadêmicos como Henry Mintzberg tiveram papel central na construção desse debate nos EUA e, posteriormente, em outros países. A principal crítica ao modelo de PE é que este impõe uma racionalidade hierárquica e autoritária que impede a participação coletiva e isola a grande empresa e seus líderes de seus clientes e colaboradores.

O modelo de GE, por sua vez, defende a troca de centralização e comando por pluralismo e aprendizagem. Este modelo foi rapidamente incorporado por grande número de consultores e acadêmicos nos EUA e isso garantiu a construção de uma nova base de legitimidade para a autoridade do estrategista na (e da) grande empresa.

Considerando as argumentações de Weber sobre a dimensão território-internacional da autoridade e da legitimidade, é possível concluir que esse debate não se referia tão-somente a problemas domésticos de empresas dos EUA. O grandioso processo de expansão internacional dos EUA ao longo dos anos 1970 demandou dos estrategistas (não somente os da grande empresa) a construção de novas bases de legitimidade, mais amplas e pluralistas, que fossem capazes de garantir novas oportunidades em um mundo não mais 'governado' pela disputa entre capitalistas e comunistas, mas por uma nova disputa, liderada pelos EUA, entre tipos de capitalismo.

\subsection{A autoridade 'pluralista' na era da gestão estratégica}

A transição de PE para GE, no início da década de 1980, foi vista por alguns como uma vitória do baixo escalão sobre a alta hierarquia. No fundo, a situação não é bem essa. Acadêmicos e consultores em GE conseguiram resguardar a autoridade do estrategista da grande empresa. $\mathrm{Na}$ aparência, houve mudanças; no fundo, a essência da legitimidade da autoridade do estrategista foi mantida. Um dos principais recursos para isso foi o conhecimento acadêmico. A literatura da área passou a descrever o ambiente externo como ainda mais complexo e ameaçador.

Um dos mais importantes autores baseados nos EUA define GE como uma abordagem sistemática que orienta o estrategista a posicionar e relacionar a empresa ao seu ambiente, de modo "a garantir seu continuado sucesso e a mantê-la protegida das surpresas" (ANSOFF, 1984, p. xv). Essa definição estabelece o entendimento de que as surpresas causadas pelo ambiente externo são o elemento mais crítico para as empresas e para o estrategista.

A imagem do estrategista como autoritário e centralizador foi substituída então por uma imagem mais 'humanizada'. A literatura de GE apresentou o estrategista como uma pessoa que pode cometer equívocos, sem que, com isso, sua posição de autoridade seja ameaçada. A descrição de ambiente externo como domínio extremamente complexo e dinâmico transformou a incerteza e a imprevisibilidade em senso comum. Sob a perspectiva daqueles sobre quem o poder é exercido, incerteza e imprevisibilidade ajudam a isentar o estrategista de responsabilidades em situações de abuso e também em casos de fracasso.

A imprevisibilidade crescente atribuída ao ambiente externo pela literatura de GE trouxe uma mudança de posição importante na área. A primeira diz respeito à inclusão de todos os indivíduos das empresas no processo da estratégia. Esse efeito seria obtido com a substituição do comprometimento da estratégia com os planos das altas hierarquias pelo comprometimento com o "desempenho real" (ANSOFF, 1991, p. 20) e com as habilidades diferençadas dos gerentes (PETERS; WATERMAN, 1983). O modelo de GE defende que todos são (ou deveriam ser) estrategistas, ainda que possam pertencer a níveis distintos na empresa, na sociedade e no mundo.

Segundo o modelo de GE, o comprometimento de todos os membros da empresa com a estratégia é obtido por meio da difusão de valores corporativos (BOURGEOIS; BRODWIN, 1984). Por isso cultura organizacional tornou-se um conceito importante na literatura da área a partir dos anos 1980. Por outro lado, foram relegadas as questões 'culturais' de natureza território-internacional que dizem respeito aos argumentos correspondentes aos de Weber acerca da legitimação e autoridade. 
Conceitos específicos, tais como visão de longo prazo e pensamento estratégico, encorajam a participação dos indivíduos e a descentralização das decisões nas empresas. Essa perspectiva cultural e humanizada explicaria a posição de superioridade de GE em relação ao modelo de PE. A cultura organizacional adequada permite o surgimento de respostas estratégicas contra as surpresas provenientes do ambiente externo e a eliminação de eventuais resistências mais complicadas.'

A representação de ambiente externo cada vez mais ameaçador na literatura de GE ajudou a promover a proliferação de escolas na área de estratégia (MINTZBERG et al., 2000) ${ }^{10}$. O pluralismo resultante foi materializado nos EUA e no exterior pelos debates apolíticos, protagonizados por autores e instituições influentes, em torno do caso Honda (ver Mintzberg et al., 1996). Outras dimensões importantes - tais como a dimensão território-internacional da legitimidade e do conhecimento acadêmico, ou os outros 'estrategistas' por trás dos bastidores naquele caso de ensino - não foram tratadas pela literatura especializada produzida nos EUA. As versões construídas e publicadas nos EUA reproduziram e difundiram os fundamentos (aparentemente) apolíticos de PE e GE.

A disputa que se viu na literatura sobre qual escola estava correta representa muito mais um duopólio, cuja principal característica é bloquear a emergência de concorrentes, do que um efetivo debate acadêmico. Esse quadro ajuda a explicar por que posições contraditórias e dicotomias teóricas e conceituais nas diferentes visões do caso não foram reconhecidas na análise do mais famoso caso de ensino de estratégia (MAIR, 1999).

No final das contas, o debate entre PE e GE ampliou a base de legitimação da autoridade do estrategista da grande empresa tanto nos EUA quanto no exterior. O debate fortaleceu a crença de que, de uma maneira ou de outra, países e sociedades se beneficiam da ação do estrategista da grande empresa e do conhecimento acadêmico correspondente. Isso ajuda a explicar a extraordinária ascensão do modelo de GE e a ausência de debates acerca da dimensão território-internacional referente à rápida e intensa difusão internacional da literatura produzida nos EUA.

Para a melhor compreensão desse processo, podemos ressaltar a existência de um duplo movimento importante nos EUA, principalmente a partir da década de 1980. Por um lado, empresas japonesas obtinham desempenho superior no mercado dos EUA frente a concorrentes locais por causa do uso de modelos mais descentralizadores que os de PE. Em paralelo, havia um processo de intensa internacionalização de grandes empresas dos EUA. A noção de 'invasão japonesa' nos EUA apagava a noção de 'invasão americana' em outros territórios. Isso quer dizer que a literatura de GE deve ser vista não apenas como um resultado do reconhecimento da supremacia do modelo japonês de gestão nos EUA, mas também como um recurso para legitimar a autoridade território-internacional do estrategista da grande empresa. Em diversos países, inclusive nos EUA, a pluralidade de GE ajudou a atenuar críticas à autoridade do estrategista da grande empresa e à área de estratégia até meados dos anos 1990.

$\mathrm{Na}$ era da globalização, o grandioso número de novas fronteiras e territórios representa um obstáculo para o exercício de autoridade do estrategista da grande empresa e aos seus estrategistas. Os crescentes ataques mobilizados por organizações não governamentais e instituições da sociedade civil à autoridade do estrategista da grande empresa e dos EUA impulsionam a área de estratégia para novos desafios. As grandes empresas dos EUA enfrentam um contexto internacional bem mais complicado do que no cenário de após a Segunda Guerra para exercer autoridade legítima. Esse cenário ajuda a explicar os novos desenvolvimentos acadêmicos que tentam transcender o duopólio PE-GE nos EUA (BARON, 2005; BRUGMANN; PRAHALAD, 2007), as tentativas, na Europa, de influenciar a agenda na área de estratégia, e também as crescentes preocupações com as economias emergentes.

\section{Legitimação da autoridade dos estrategistas no Brasil}

A disciplina de estratégia foi introduzida no Brasil na década de 1960 para suprir uma deficiência dos cursos de administração. Para isso foram amplamente usados o modelo de ensino baseado em casos e os livros-texto produzidos nos EUA (BERTERO et al., 2003). O crescimento do tamanho de empresas nacionais e subsidiárias de multinacionais nas décadas de 1960 e 1970, e a necessidade de modernização dos mecanismos de 
coordenação e controle dessas empresas, criaram um contexto favorável para a adoção do modelo de PE no Brasil.

O período de estagnação da economia mundial nos anos 1980 e a emergência do modelo de GE nos EUA a partir da 'invasão' japonesa ajudaram a abalar a confiança das empresas e dos estrategistas em PE no Brasil. O debate entre PE e GE ajudou a aumentar o domínio, no Brasil, da literatura produzida nos EUA.

Algumas críticas a respeito do domínio do conhecimento produzido nos EUA no país foram publicadas recentemente (BERTERO et al., 2003; BIGNETTI; PAIVA, 2002), mas ainda sem a problematização, sob uma perspectiva território-internacional, das bases da autoridade legítima do estrategista e da grande empresa, e do papel político-ideológico cumprido pelo conhecimento acadêmico.

O cenário atual no Brasil é particularmente propício para esse tipo de questionamento. A partir do início da década de 1990, ocorreu no país uma transição profunda em termos de ordem social. Essa transição é de certa forma similar ao que ocorrera na Revolução Francesa e nos processos correspondentes problematizados por Weber. O modelo de economia política centrada no Estado foi substituído de forma acelerada no Brasil (e em outros países) por um modelo centrado no mercado (DINIZ; BOSCHI, 2003). Essa transformação, impulsionada pela globalização da economia, pelo interesse dos estrategistas das economias tidas como mais desenvolvidas em construir bases de legitimidade nas economias emergentes, e pelos ataques à autoridade da grande empresa em economias emergentes, exigiu a construção de novas bases de autoridade e legitimidade para a grande empresa e para seus estrategistas.

Assim como em outras economias emergentes, a partir de meados da década de 1980, o Estado passou a ser descrito no Brasil como incompetente e ineficiente (DINIZ; BOSCHI, 2003). Privatizações de empresas estatais, reforma do Estado e processos abertura econômica marcaram a instalação da era da globalização no país. A entrada de grandes empresas estrangeiras no Brasil, especialmente por meio da privatização, e a entrada de grandes volumes de investimentos diretos estrangeiros tiveram o suporte do conhecimento acadêmico da área de estratégia. De fato, essas transformações foram precedidas e suportadas pelo estabelecimento do duopólio PE-GE no Brasil, e pelo correspondente bloqueio de abordagens críticas que pudessem reconhecer os fundamentos dos ataques à autoridade da grande empresa e de seus estrategistas na era da globalização e também a preocupação dos EUA com a influência das economias emergentes sobre o futuro do capitalismo.

Ainda que não haja um consenso na literatura sobre o conceito de economia emergente (HOSKISSON et al., 2000), instituições e analistas nos EUA - incluindo acadêmicos ilustres de esquerda e de direita, além do próprio governo (JARVIS, 2006) - advertem que economias emergentes cumprirão um papel central para o futuro do capitalismo. Por causa disso o grupo de economias emergentes mais conhecidas (incluindo países como Rússia, China, Índia, Brasil e África do Sul) acabou se transformando em alvo preferencial, tanto para estrategistas de grandes empresas quanto para acadêmicos e instituições acadêmicas dos EUA e de outras economias tidas como desenvolvidas (BRODY, 2007).

Nas economias emergentes, os papéis do Estado, do mercado e das demais instituições não coincidem necessariamente com o que os modelos dominantes produzidos nos EUA descrevem e prescrevem. Isso ajuda a explicar por que vem sendo construída, pela literatura produzida nos EUA, a crença de que as empresas que atuam sob a lógica do mercado livre têm desempenho superior às empresas administradas diretamente pelo Estado - a despeito das evidências contrárias (BURAWOY; LUKACS, 1985). De fato, não é correta a avaliação dominante na literatura produzida nos EUA de que essa característica torna inferiores outros tipos de economia política (CHANG, 2002). Apesar de serem incentivadas a adotarem modelos econômicos centrados nas noções de livre mercado e de grande empresa, as economias emergentes são marcadas pela forte presença do Estado e de organizações governamentais no mercado (HOSKISSON et al., 2000; CHANG, 2002).

Nesse cenário de disputas território-internacionais, em que o conhecimento acadêmico cumpre um papel de central importância em termos políticos e ideológicos, é importante questionar a autoridade do duopólio PE-GE no Brasil e em outras economias emergentes. Também é importante questionar as tentativas recentes, na literatura de estratégia produzida nos EUA, de transcender esse duopólio. Uma das questões centrais é que a literatura produzida nos EUA tende a proteger a entrada de investimentos diretos de empresas estrangeiras em 
economias emergentes e a privilegiar a grande empresa e seus estrategistas, em detrimento da saída de investimentos diretos feitos por grandes empresas de economias emergentes e dos interesses dos diferentes tipos de estrategistas que fazem parte dessas economias. Em outras palavras, a área acaba privilegiando o processo de globalização em uma determinada direção.

Mais especificamente, o conhecimento dominante em estratégia legitima o modelo de economia política centrada no mercado e bloqueia em economias emergentes o desenvolvimento de modelos e conceitos que reconheçam o papel do governo no mercado e as fronteiras cada vez menos nítidas entre esses domínios.

Esse quadro é extremamente desafiante para estrategistas e para a área de estratégia no Brasil e em outras economias emergentes. Um crescente número de acadêmicos e consultores dos EUA vem perseguindo a liderança na produção de conhecimento em estratégia em economias emergentes (HOSKISSON et al., 2000; KHANNA et al., 2005; SINHA, 2005; BRUGMANN; PRAHALAD, 2007). Em outras palavras, a academia de estratégia dos EUA está construindo novas bases de legitimidade e autoridade na era da globalização por meio de um processo de expansão território-internacional que torna o trabalho de Weber particularmente importante para a construção de agendas na área no Brasil.

Até o início da década de 1990, grande parte dos estrategistas no Brasil estava em empresas estatais e no governo. De certa maneira, cumpria-se no país a ordem social estabelecida pelos princípios do Estado moderno. Segundo os textos dominantes, a era da globalização torna esses estrategistas obsoletos. Correspondentemente, o conhecimento acadêmico em estratégia produzido nos EUA reproduz dois pressupostos importantes: (a) estrategistas do mundo público devem ser substituídos por estrategistas da grande empresa e (b) outros tipos de capitalismo devem ser substituídos pelo modelo de capitalismo dos EUA.

Em uma economia política que conta com reduzido número de grandes empresas, em que o mercado conta com forte presença do Estado e não detém uma posição forte em termos de produção e difusão de conhecimento acadêmico em estratégia, esses pressupostos devem ser problematizados no Brasil. É importante ressaltar um problema central: a autoridade de estrategistas importantes em economias emergentes vem sendo deslegitimada pela área de estratégia há algumas décadas. A área também vem deslegitimando outros tipos de organização que desafiam a natureza da grande empresa e que são de central importância em economias emergentes, tais como organizações estatais e de capital misto.

Alguns acadêmicos de outras áreas, que reconhecem a realidade das economias emergentes e desafiam os pressupostos do conhecimento em estratégia produzido nos EUA, devem ser ouvidos pela área de estratégia no Brasil. Enquanto a maioria dos pesquisadores da área de estratégia no Brasil reproduz os conhecimentos e debates produzidos nos EUA, esses acadêmicos brasileiros de outras áreas ressaltam que um dos principais problemas do país é a ausência de estrategistas e de estratégias de desenvolvimento nacional (ARBIX et al., 2002; DINIZ; BOSCHI, 2003).

\section{Considerações finais}

Este ensaio mostrou a importância dos conceitos de autoridade e legitimidade para estrategistas e para a área de estratégia. Por meio do resgate do trabalho de Weber e da análise crítica do debate entre PE e GE (descrito neste ensaio como um duopólio), os autores mostraram a importância da legitimidade e da autoridade para a constituição da área de estratégia nos EUA e para a expansão território-internacional da grande empresa e seus estrategistas.

Alguns autores concordam com o argumento de que as práticas e o conhecimento de estratégia têm importantes implicações para a sociedade, mas pouco se fala sobre implicações político-econômicas e territóriointernacionais relacionadas ao domínio dos EUA na área. Este artigo mostrou que esse tipo de questionamento é de central importância em (e para) economias emergentes.

$\mathrm{Na}$ era da globalização, o conhecimento acadêmico é um recurso cada vez mais importante para a construção da autoridade do estrategista nos contextos e territórios que compõem o amplo e complexo mercado global. Os 
autores deste ensaio mostraram que um grande desafio atual para a maioria das economias emergentes, como o Brasil, é o reconhecimento da importância de outros tipos de estrategistas e de organizações que foram marginalizados pela literatura produzida nos EUA.

A base de legitimidade construída pela tese de capitalismo gerencial ou de mercado, desenvolvida nos EUA, fez com que a área passasse a ser tratada como strategic management (com foco no mercado e na grande empresa) em vez de, por exemplo, strategic administration (com foco no Estado e na administração pública). Em economias emergentes, onde é grande a presença do Estado sobre o mercado e vice-versa, a base construída nos EUA é problemática porque marginaliza outros tipos de estrategistas e privilegia um modelo específico de grande empresa e de capitalismo. Este ensaio sugere que seria mais correto a academia no Brasil denominar a área de 'gestão e administração estratégica' (tradução para 'strategic management and administration') para que os diferentes tipos de estrategistas que constituem uma economia emergente pudessem ser representados.

Este ensaio mostrou como o debate PE-GE contribuiu em termos políticos e ideológicos para a construção de bases de autoridade legítima para estrategistas da grande empresa nos EUA e, em seguida, em diversos países. Esse debate, ao ser reproduzido em economias emergentes, tende a ser desfavorável para os diferentes tipos de estrategistas que fazem parte dessas economias.

Este ensaio nos leva então a algumas questões importantes que poderiam fazer parte de agendas de pesquisa na área no Brasil (e em outras economias emergentes).

a) Quem é estrategista no Brasil? Mais especificamente, quem são os estrategistas no Brasil que devem ser reconhecidos pela literatura de estratégia?

b) Até que ponto a grande empresa privada deve ser tratada como foco único e exclusivo pela área de estratégia no Brasil? Como o foco em organizações públicas, organizações mistas e em mercados regulados, por exemplo, poderia fortalecer a área e torná-la mais relevante no Brasil e influente no âmbito internacional?

c) Até que ponto as economias emergentes, a despeito das características específicas e da diversidade de classificações na literatura, apresentam padrões comuns que justificam o desenvolvimento de conhecimento em estratégia voltado para esse contexto?

d) Até que ponto a academia dos EUA deve liderar o processo de produção acadêmica em e para economias emergentes? Correspondentemente, até que ponto os acadêmicos das economias emergentes devem buscar a liderança na produção de conhecimento em e para economias emergentes e na construção de projetos de cooperação com pesquisadores da Europa?

Políticos, gestores públicos, diplomatas, ministros, entre outros, que também são estrategistas no Brasil, não deram a devida atenção para o processo de construção e expansão da área de estratégia no país. Isso pode ajudar a explicar não somente as dificuldades enfrentadas pela área no Brasil para um desenvolvimento nacional mais efetivo, mas também o desempenho ainda tênue de organizações brasileiras - privadas, estatais, mistas e não governamentais - na era da globalização ${ }^{11}$.

Este ensaio sugere que a análise e a construção da autoridade do estrategista por meio de bases de legitimidade mais compatíveis com a realidade de economias emergentes na era da globalização é um importante foco para pesquisadores no Brasil. Para isso, pesquisadores devem promover desenvolvimentos interdisciplinares com áreas que representam os estrategistas que foram marginalizados (ou deslegitimados) pela literatura produzida nos EUA e também promover intercâmbios, na área de estratégia e em outras áreas do conhecimento, com outras economias emergentes. Ciência política, relações internacionais, algumas correntes de sociologia, teoria de elites, economia política, entre outras áreas, podem ser úteis para esse processo de construção de conhecimento na área. 


\section{Referências}

ALVESSON, M.; DEETZ, S. Doing critical management research. London: Sage, 2000.

ANSELL, C. Legitimacy: political. In: SMELSER, N.; BALTES, P. (Eds.). International encyclopedia of the social \& behavioral sciences. Oxford: Elsevier, 2001.

ANSOFF, I. Implanting Strategic Management. New York: Prentice Hall, 1984.

ANSOFF, H. Critique of Henry Mintzberg's 'The design school: reconsidering the basic premises of strategic management'. Strategic Management Journal, v. 12, p. 449-461, 1991.

ARBIX, G. et al. (Orgs.). Brasil, México, África do Sul, Índia e China: diálogo entre os que chegaram depois. São Paulo: UNESP; USP, 2002. ARENDT, H. What is authority. In: BAEHR, P. The portable Hannah Arendt. Harmondsworth: Penguin, 2000.

ASFORTH, B.; GIBBS, B. The double-edge of organizational legitimation. Organization Science, v. 1, n. 2, p. 177-194, 1990.

AULAKH, P.; KOTABE, M.; TEEGEN, H. Export strategies and performance of firms from emerging countries. Academy of Management Journal, v. 42, n. 3, p. 342-361, 2000.

BAILEY, E. Integração das Tendências Políticas na Vantagem Dinâmica. In: DAY, G.; REIBSTEIN, D. A Dinâmica da estratégia competitiva. Rio: Campus, 1999.

BARON, D. Business and its environment. $5^{\text {th }}$. ed. New Jersey: Prentice Hall, 2005.

BERTERO, C.; VASCONCELOS, F.; BINDER, M. Estratégia empresarial: a produção científica brasileira entre 1991 e 2002 . Revista de Administração de Empresas, v. 43, n. 4, p. 48-62, 2003.

BIGNETTI, L.; PAIVA, E. Ora (Direis) Ouvir Estrelas!: Estudo das Citações de Autores de Estratégia na Produção Acadêmica Brasileira. Revista de Administração Contemporânea, v. 6, n. 1, p. 105-125, 2002.

BOURGEOIS, L.; BRODWIN, D. Strategic implementation: five approaches to an elusive phenomenon. Strategic Management Journal, v. 5 , p. 241-264, 1984.

BRODY, W. College Goes Global. Foreign Affairs, v. 86, n. 2, 2007.

BROWN, A. Politics, symbolic action and myth making in pursuit of legitimacy. Organization Studies, v. 15, n. 6, p. 861-878, 1994.

BRUGMANN, J.; PRAHALAD, C. New social compact. Harvard Business Review, v. 85, n. 2, p. 80-90, 2007.

BURAWOY, M.; LUKACS, J. Mythologies of work: a comparison of firms in State socialism and advanced capitalism. American Sociological Review, v. 50, p. 723-737, 1985.

CHANDLER, A. D. Strategy and structure. Cambridge: MIT Press, 1962.

. The visible hand. Cambridge: Belknap Press, 1977.

The emergence of managerial capitalism. Business History Review, v. 58, n. 4, p. 473-503, 1984.

CHANG, Ha-Joon. Rompendo o modelo. In: ARBIX, G.; COMIN, A.; ZILBOVICIUS, M.; ABRAMOVAY, R. (Orgs.). Brasil, México, África do Sul, Índia e China: diálogo entre os que chegaram depois. São Paulo: UNESP; USP, 2002.

COHEN, J.; HAZELRIGG, L.; POPE, W. De-parsonizing Weber: a critique to Parsons' interpretation of Weber's sociology. American Sociological Review, v. 40, p. 229-241, 1975.

COHN, G. Introdução. In: COHN, G. (Org.). Weber. 6. ed. São Paulo: Ática, 1997.

COWLING, K.; TOMLINSON, P. Globalisation and corporate power. Contributions to Political Economy, v. 24, p. 33-54, 2005.

CRAIG, D.; PORTER, D. The third way and the third world: poverty reduction and social inclusion strategies in the rise of 'inclusive' liberalism. Review of International Political Economy, v. 12, n. 2, p. 226-263, 2005.

D'AVENI, R. Corporate spheres of influence. Sloan Management Review,v. 45, p. 38-46, 2004.

DAVIS, I. "Soft" leadership in business. McKinsey Quarterly, n. 2, p. 4-5, 2006.

. Learning to grow again. McKinsey Quarterly, n. 1, p. 125-128, 2004.

DELLA FAVE, L. Toward an explication of the legitimation process. Social Forces, v. 65, n. 2, p. 476-500, 1986. 
DIMAGGIO, P.; POWELL, W. The iron cage revisited: institutional isomorphism and collective rationality in organizational fields. American Sociological Review, v. 48, 1983.

DINIZ, E.; BOSCHI, R. Empresariado e estratégias de desenvolvimento. Revista Brasileira de Ciências Sociais, v. 18, n. 52, p. 15-33, 2003.

DYZENHAUS, D. Hobbes and the legitimacy of law. Law \& Philosophy, v. 20, n. 5, p. 461-498, 2001.

ELSBACH, K.; SUTTON, R. Acquiring organizational legitimacy through illegitimate actions: a marriage of institutional and impression management theories. Academy of Management Journal, v. 35, n. 4, p. 699-738, 1992.

FALLON, R. Legitimacy and constitution. Harvard Law Review, v. 118, p.1789-1853, 2005.

FAORO, Raymundo. Assembléia constituinte. 2. ed. São Paulo: Brasiliense, 1982.

FARIA, A. Mercado de Idéias. GV Executivo, v. 5, p. 32-37, 2006.

FOURNIER, V.; GREY, C. At the critical moment: conditions and prospects for critical management studies. Human Relations, v. 53, n. 1, p. 7-32, 2000.

FOX, T. Corporate social responsibility and development: in quest of an agenda. Development, v. 47, n. 3, p. 29-36, 2004.

GILPIN, R. 0 desafio do capitalismo global. Rio de Janeiro: Record, 2004.

HAMBRICK, D. The disintegration of strategic management: it's time to consolidate our gains. Strategic Organization, v. 2, n. 1, p. 91-98, 2004.

HOLAN, P.; MINTZBERG, H. Management as life's essence: 30 years of The Nature of Managerial Work. Strategic Organization, v. 2, n. 2, p. 205-212, 2004.

HÖPFL, H. Power, authority and legitimacy. HRDI, v. 2, n. 3, p. 217-234, 1999.

HOSKISSON, R. E.; EDEN, L.; LAU, C. M.; WRIGHT, M. Strategy in emerging economies. Academy of Management Journal, v. 43, n. 3, p. 249-267, 2000.

HUTCHCROF, P. Centralization and decentralization in administration politics: assessing territorial dimension of authority and power. Governance, v. 14, p. 23-53, 2001.

JARVIS, D. Multinational enterprise, power and the state: The costs, benefits, and consequences of globalization. Australian Review of Public Affairs, 4 Dec. 2006. Disponivel em: <http://www.australianreview.net/digest/2006/12/jarvis.html>. Acesso em: 10 maio 2007.

KHANNA, T.; PALEPU, K. Emerging giants: building world-class companies in developing countries. Harvard Business Review, v. 84, n. 10, p. 60-69, 2006.

KHANNA, T.; PALEPU, K.; SINHA, J. Strategies that fit emerging markets. Harvard Business Review, v. 83, n. 2, p. 63-76, 2005.

KNIGHTS, D.; MORGAN, G. Corporate strategy, organizations, and subjectivity: a critique. Organization Studies, v. 12, n. 2, p. 251-273, 1991.

LEVY, D.; ALVESSON, M.; WILLMOT, H. Critical approaches to strategic management. In: ALVESSON, M.; WILLMOT, H. Studying management critically. London: Sage, 2003.

LOCKE, R. The collapse of the American management mystique. Oxford: Oxford, 1996.

MAHAJAN, V.; BANGA, K. A Solução dos 86\%. Porto Alegre: Bookman, 2006.

MAIR, A. Learning from Honda. Journal of Management Studies, v. 36, n. 1, p. 25-38, 1999.

MILLS, A.; HATFIELD, J. From imperialism to globalization: internationalization and the management text. In: CLEGG, S. R.; IBARRACOLADO, E.; BUENO-RODRIQUEZ, L. (Eds.). Global management: universal theories and local realities. London: Sage, 1999.

MINTZBERG, H., AHLSTRAND, B.; LAMPEL, J. Safári de estratégia: um roteiro pela selva do planejamento estratégico. Porto Alegre: Bookman, 2000.

MINTZBERG, H. et al. The Honda effect. California Management Review, v. 38, n. 4, p. 78-92, 1996.

ORGAN, D. Linking pins between organizations and environments. Business Horizons, v. 14, n. 6, p. 73-80, 1971.

PETERS, T.; WATERMAN, R. Em busca da excelência. São Paulo: Harper \& Row, 1983.

PETTIGREW, A.; THOMAS, H.; WHITTINGTON, R. (Eds.). Handbook of strategy and management. London: Sage, 2003. 
PFEFFER, J.; SALANCIK, G. The external control of organizations: a resource dependence perspective. $2^{\text {nd }}$. ed. New York: Harper \&t Row, 2003.

POLLARD, S. The genesis of modern management. Harmondsworth: Penguin Books, 1968.

PORTER, M.; KRAMER, M. Strategy and society: the link between competitive advantage and corporate social responsibility. Harvard Business Review, v. 84, n.12, p. 78-92, 2006.

PRASAD, A. (Ed.). Postcolonial theory and organizational analysis. New York: Palgrave, 2003.

RICHTER, M. Toward a concept of political illegitimacy. Political Theory, v. 10, n. 2, p. 185-214, 1982.

ROPER, J. Symmetrical Communication: Excellent Public Relations or a Strategy for Hegemony? Journal of Public Relations Research, v. 17, n. 1, p. 69-86, 2005.

SCAFF, L. On Richter, "Toward a concept of political illegitimacy". Political Theory, v. 11, n. 1, p. 133-136, 1983

SCHERER, A. Pluralism and incommensurability in Strategic Management and Organization Theory: a problem in search of a solution. Organization, v. 5, p. 147-168, 1998.

SHOKER, A. D.; SETHI, S. P. An approach to incorporating social references in developing corporate action strategies. In: SETHI, S. P. (Ed.). The unstable ground: corporate social policy in a dynamic society. Los Angeles: Melville, 1974.

SHRIVASTAVA, P. Is strategic management ideological? Journal of Management, v. 12, n. 3, p. 363-377, 1986.

SANTOS, B. de S. Um discurso sobre as ciências. 13. ed. Porto: Afrontamento, 2002.

SINGHVI, S. Authority and power. Advanced Management Journal, v. 34, n. 3, p. 64-71, 1969.

SINHA, J. Global champions from emerging markets. McKinsey Quarterly, n. 2, p. 26-35, 2005.

STARKEY, K.; TEMPEST, S. Bowling along: strategic management and social capital. European Management Review, v. 1, n. 1, p. 78-83, 2004.

STEINER, G.; MINER, J. Política e estratégia administrativa. São Paulo: Interciência, 1977.

TYLER, T. Psychological perspectives on legitimacy and legitimation. Annual Review of Psychology, v. 57, p. 375-400, 2006.

VAN AGTMAEL, A. The emerging markets century: how a new breed of world-class companies is overtaking the world. New York: Free Press, 2007.

WEBER, M. A "objetividade" do conhecimento nas ciências sociais. In: COHN, G. (Org.). Weber. 6. ed. São Paulo: Ática, 1997.

Ciência e política: duas vocações. São Paulo: Martin Claret, 2001.

. Economía y sociedad. México: Fondo de Cultura Económica, 2004.

A ética protestante e o espírito do capitalismo. São Paulo: Cia das Letras, 2005.

WhITINGTON, R. Estratégia Após o Modernismo: Recuperando a Prática. Revista de Administração de Empresas, v. 44, n. 4, p. 44-53, 2004.

WHITINGTON, R. et al. Taking strategy seriously. Journal of Management Inquiry, v. 12, n. 4, p. 396-409, 2003.

WORDEN, S. The role of religious and nationalist ethics in strategic leadership: the case of J. N. Tata. Journal of Business Ethics, v. 47, p. 147-164, 2003.

WREN, D. The evolution of management thought. New York: John Wiley, 1994.

WRIGHT, M. et al. Strategy research in emerging economies: challenging the conventional wisdom. Journal of Management Studies, v. 42, n. 1, p. 1-33, 2005.

\footnotetext{
${ }^{1}$ Obviamente, o cenário contemporâneo é mais favorável para estrategistas de países tidos como mais desenvolvidos do que para estrategistas de economias emergentes ou menos desenvolvidos. Isso ajuda a explicar por que (a) é cada vez mais comum a construção de legitimidade das grandes empresas por meio de ações ilegítimas (ELSBACH; SUTTON, 1992), (b) a literatura focada em legitimidade segue uma abordagem predominantemente apolítica (SUCHMAN, 1995), e (c) a literatura européia vem disputando a autoridade dos EUA na área de estratégia (WHITTINGTON, 2004; STARKEY e TEMPEST, 2004). Na era da globalização, a estratégia como campo de conhecimento acadêmico passou a ser de central importância não somente para empresas, mas também para organizações públicas, instituições internacionais e organizações não governamentais (WHITTINGTON et al., 2003).
} 
${ }^{2}$ Em grande parte, esse foco ajuda a explicar a importância do trabalho de Chandler (1977; 1962) e da Harvard Business School para a área de estratégia.

${ }^{3}$ O conhecimento da área passou a ser questionado no que diz respeito ao domínio dos EUA (WHITTINGTON, 2004), à falta de relevância para os estrategistas (HAMBRICK, 2004; BERTERO et al., 2003) e à fragilidade de sua pretensa neutralidade política (WHITTINGTON et al., 2003).

${ }^{4}$ A literatura pós-colonialista em administração - que se concentra ainda no campo de estudos organizacionais - é um interessante exemplo da importância de uma postura crítica em relação ao conhecimento dominante em economias emergentes (ver MILLS; HATFIELD, 1999; PRASAD, 2003).

5 A ação social caracteriza-se por se orientar pelas ações de outros, sejam passadas, presentes ou esperadas como futuras (WEBER, 2004). Essas ações adquirem sentido próprio ao serem dirigidas à ação de outros. A abordagem de prática social, por outro lado, procura analisar como atividades e interações entre pessoas constroem as práticas.

${ }^{6}$ O tipo ideal mais conhecido de Weber, a burocracia, ainda hoje é interpretado equivocadamente como um conjunto de regras a serem seguidas, o que demonstra certo desconhecimento e dificuldades na compreensão dos pressupostos metodológicos desse autor.

${ }^{7}$ A coerção e a violência física não são, a priori, manifestações de autoridade legítima porque estão alicerçadas no terror e no medo. Com autoridade legítima, o poder se torna mais furtivo; ou seja, o exercício do poder acaba naturalizando-se nas relações sociais e tornandose 'invisível' para os constituintes. Isso ajuda a explicar a importância 'estratégica' do conhecimento acadêmico na área de estratégia.

${ }^{8}$ Curiosamente, as críticas ao modelo de PE não se construíram nos países que foram 'invadidos' pelas grandes empresas dos EUA e por seus estrategistas (nem nos países que foram 'invadidos' por outros estrategistas dos EUA).

${ }^{9}$ Com base na 'cultura corporativa' privilegiada pelo modelo de GE, cabe aos estrategistas o papel mais amigável de 'treinador': "Como um time de basquete, há um contínuo ajustamento mútuo entre unidades organizacionais enquanto o 'jogo' evolui ao redor do movimento de todos os membros. Toda essa atividade se dá na busca da visão essencial estabelecida pelo gerente sênior" (BOURGEOIS; BRODWIN, 1984, p. 251).

${ }^{10}$ Repetidos ataques ao positivismo na área de sociologia nas décadas de 1970 e 1980 e, posteriormente, na área de administração, também explicam em parte o pluralismo que emergiu nessa época na área de estratégia.

11 A área de estratégia no Brasil e os estrategistas que foram esquecidos pela área devem refletir sobre as questões territóriointernacionais apontadas neste artigo, tendo em vista a posição do país como economia emergente. Um risco potencial de não fazê-lo é a subordinação na economia política global. Um risco potencial de fazê-lo é provocar reações que acabariam levando ao mesmo quadro de subordinação. Uma posição intermediária ou híbrida, típica em economias emergentes, pode ajudar a resolver esse aparente impasse. Inspirado em Weber, os autores deste ensaio argumentam que se pode simular a lealdade a certas crenças estabelecidas pelo conhecimento na área de estratégia construído nos EUA. Entretanto, essa simulação deve ser feita com critério. Praticantes e acadêmicos no Brasil devem reconhecer que algumas das crenças seguidas nos EUA são virtuosas e legítimas; outras, entretanto, podem e devem ser questionadas, mesmo que em silêncio. 